OECD Regional Development Working Papers 2017/01

The impact of road infrastructure investment on incumbent firms in Korea
Alexander C. Lembcke, Carlo Menon 


\section{OECD REGIONAL DEVELOPMENT WORKING PAPERS}

This series is designed to make available to a wider readership selected studies on regional development issues prepared for use within the OECD. Authorship is usually collective, but principal authors are named. The papers are generally available only in their original language English or French with a summary in the other if available.

OECD Working Papers should not be reported as representing the official views of the OECD or of its member countries. The opinions expressed and arguments employed are those of the author(s).

This document and any map included herein are without prejudice to the status of or sovereignty over any territory, to the delimitation of international frontiers and boundaries and to the name of any territory, city or area.

Working Papers describe preliminary results or research in progress by the author(s) and are published to stimulate discussion on a broad range of issues on which the OECD works. Comments on Working Papers are welcomed, and may be sent to either gov.contact@oecd.org or the Public Governance and Territorial Development Directorate, OECD, 2 rue André-Pascal, 75775 Paris Cedex 16, France.

Authorised for publication by Rolf Alter, Director, Public Governance and Territorial Development Directorate, OECD.

OECD Regional Development Working Papers are published on http://www.oecd.org/gov/regional/workingpapers

Applications for permission to reproduce or translate all or part of this material should be made to: OECD Publishing, rights@oecd.org or by fax 33145249930.

(C) OECD 2017 


\title{
THE IMPACT OF ROAD INFRASTRUCTURE INVESTMENT ON INCUMBENT FIRMS IN KOREA
}

\author{
By Alexander C. Lembcke ${ }^{1}$ and Carlo Menon ${ }^{2}$
}

\begin{abstract}
This paper develops an indicator that combines the area that residents can reach within a certain time of travel with population density to create a proxy for "accessibility", i.e. access to employment and consumption opportunities. Using a large scale firm level dataset, with nearly one million firm year observations over 14 years, the paper quantifies the link between firm-level outcomes and the change in accessibility in Korea due to the expansion of the network of major roads. The results suggest that the most productive firms benefited in terms of employment, output, and productivity, as accessibility improved. For the majority of incumbent firms, improved accessibility leaves most balance sheet variables broadly unaffected, but is associated with a decrease in fixed assets. The estimates also suggest that there was little job displacement, with the exception of service sectors where employment increased in response to improved local accessibility and declined for long distance accessibility.
\end{abstract}

Key words: Accessibility, roads, highways, firm-level data, employment, productivity, capital, Korea

JEL classifications: R12, R32, R40, L23

\footnotetext{
${ }^{1}$ OECD Public Governance and Territorial Development Directorate (alexander.lembcke@oecd.org);

${ }^{2}$ OECD Science, Technology and Innovation Directorate (carlo.menon@oecd.org)
}

The authors would like to thank the Korean Ministry of Land, Infrastructure and Transport and its representatives for supporting this work. Particular thanks go to Peter Gal who supported the work with his comments, code and expertise on the ORBIS database, Luigi Biagini who expertly handled the digitisation of historical maps, and to Rosa Sanchis-Guarner for helpful advice. Useful comments and discussions during various stages of the project were received by OECD officials from the OECD Economics Department, the Public Governance and Territorial Development Directorate and the OECD Science, Technology and Innovation Directorate. This paper does not reflect the official views of the OECD or of its member countries. The opinions expressed and arguments employed are those of the authors and all faults are their responsibility. Working Papers describe preliminary results or research in progress by the author(s) and are published to stimulate discussion on a broad range of issues on which the OECD works. Comments are welcomed and may be sent to the authors.

Note: This working paper was drafted over the course of two years and part of its output has been published in the OECD report "Road infrastructure, traffic safety and inclusive development in Korea" (OECD, 2016a). This draft was updated using the newest available data for the commercial ORBIS database provided by the Bureau van Dijk. 


\section{TABLE OF CONTENTS}

\begin{tabular}{|c|}
\hline .................4 \\
\hline 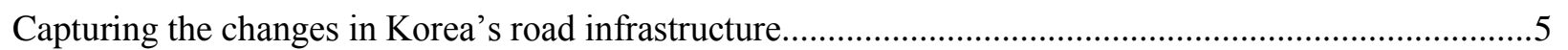 \\
\hline 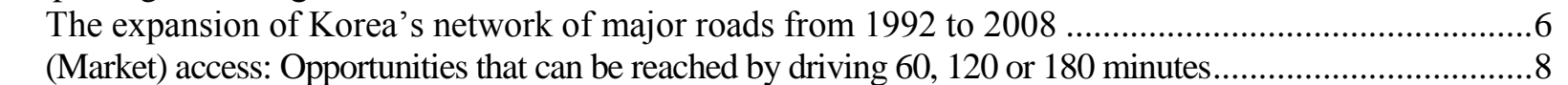 \\
\hline Estimating the impact of improved (market) access on incumbent firms in Korea \\
\hline Data on Korean firms \\
\hline 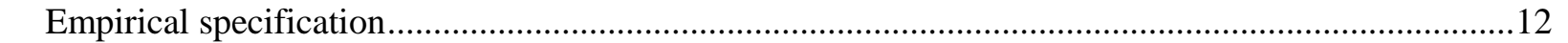 \\
\hline 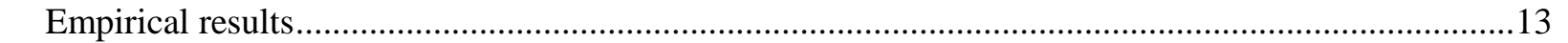 \\
\hline Conclusion \\
\hline
\end{tabular}




\section{Introduction}

Transport infrastructure investment is often an important component of policies for regional development and for balancing the centripetal forces of economic integration. But supply and demand for transport infrastructure within a country is generally far from homogenous, and there is significant potential to improve access to jobs and services through better targeted investments combined with transport policies that focus on access rather than mobility per se. This is the case at regional scale, but also for cities and their surrounding commuting zones: well-developed, reliable, and accessible urban transport systems are central to increasing worker and employer benefits through widening the scope for better matching skills and jobs.

This paper aims to further the understanding of the mechanisms that link the development of road infrastructure and economic outcomes. In particular, it assesses how improvements in "accessibility" - a broad measure for access to markets, workers and opportunities - has affected incumbent firms in Korea. In studying the impact of infrastructure investment, Korea is a particularly interesting setting as the road rapidly developed in the decades since the first expressway was completed in 1970 and construction continues in the pursuit to develop a 7x9 expressway network across Korea. It uses a large-scale firm-level dataset, which, after excluding those with missing values, contains nearly 400000 firm-year observations for manufacturing firms and more than 570000 for service sector firms over 14 years. Crucially, the dataset allows following the same firm over time ("panel data"); this opens up the possibility to use empirical strategies that enable to control for all time-invariant firm characteristics that affect outcomes at the firm level.

The results of the empirical analysis suggest that the most productive firms seem to have benefited in terms of employment, output, and productivity, as accessibility improved. For the majority of incumbent firms the improved accessibility leaves most balance sheet variables broadly unaffected, but is associated with a decrease in fixed assets. The results also suggest that there was little job displacement, with the exceptions of service sectors where employment increased in response to improved local accessibility (i.e. less than 60 minutes of driving) and declined for long distance accessibility (120-180 minute drives).

The remainder of this section motivates the role of infrastructure for regional development, through the lens of market access and agglomeration economies. The second section describes the development of road infrastructure in Korea and highlights the change in the network of the fastest type of roads, expressways, in particular. The section then outlines how the change in the road network is used to construct an indicator for "accessibility". The third section presents the empirical specification that links accessibility with firm-level outcomes for incumbent firms. The final section discusses the results and concludes.

\section{Transport infrastructure, agglomeration and the local economy}

Transport infrastructure investment affects the local economy through two channels: the construction process itself and - more importantly - changes to the characteristics of an area and its attractiveness for firms and residents. Major construction works, like the development of a new expressway, creates jobs and demand for inputs, directly raising local economic activity. This increase in economic activity is not limited to the construction sector, but planning, logis tics and other services surrounding the project will benefit. These effects can be sizeable, especially in rural areas.

However, the most important effect should arise from the opportunities that new infrastructure creates for its users. Benefits accrue to users of the road network by reducing travel time or vehicle operating costs. The market process ensures that benefits are diffused to the wider economy, e.g. land 
prices increase in better connected areas or firms pass on transport cost savings to their customers by reducing prices. An important channel that is often neglected is that transport infrastructure can help create agglomeration economies - i.e., positive economic externalities created by bringing a large number of people and firms close to each other. These effects can be large, as e.g. found by Redding and Sturm (2008) for Germany. Traditionally, these benefits arise from minimising the distance and therefore transport costs between firms and their suppliers. In modern production, the depth of the pool of qualified and locally available workers and especially the capacity to exchange knowledge and learn from other firms and people have become more important in creating agglomeration economies.

Three mechanisms create agglomeration economies (Duranton and Puga, 2004). First, by locating in close proximity, firms can share suppliers, thereby allowing them to specialise and through that specialisation become more productive. Second, large cities are home to a variety of workers and firms, which creates more opportunities for workers to find the ideal job and for firms to find the "best matching" - most productive - employee for a job. Third, informal interaction and learning from others is facilitated by proximity. This creates knowledge spillovers and therefore better diffusion of ideas and technologies. Especially in economies that move further into knowledge intensive production, the availability of skilled workers and the knowledge that can be shared locally is becoming increasingly important.

Estimates for agglomeration economies show a direct link between city size and productivity. A study of five OECD countries finds that the productivity of workers is expected to be $2-5 \%$ higher when moving to a city that is twice the size of their current hometown (Ahrend et al., 2014). There is however noticeable variation across countries in the observed size of the agglomeration economies. For the United States, bigger cities are more productive cities. But in other countries, for example the United Kingdom, the pattern would seem to be less pronounced. In the case of the United Kingdom, some small cities create agglomeration economies similar to those of London. A closer look at these highly productive cities reveals however that they are located very close to London, all within an hour's drive. The ease of access to the United Kingdom's largest city allows smaller cities to "borrow" agglomeration economies.

The impact of agglomeration economies is not limited to cities. It can create growth in well-connected surrounding regions. Across 600 European TL3 regions, ${ }^{1}$ OECD research shows that regions without a major urban agglomeration, but located close to one, have experienced stronger per capita GDP growth than other areas (Ahrend and Schumann, 2014). The positive impact declines with distance. Per capita GDP in regions within 45 minutes driving distance of a large metro area grew on average by more than $1.8 \%$ per year, in the $45-90$ minute driving range the average was about $1.3 \%$. In remote regions, located more than 5 hours from a large metro area, growth averaged less than $0.9 \%$ per year, less than half of the growth experienced in well-connected regions. Crucially, it is the driving distance, rather than geographical distance, that proves to be the better predictor for growth.

\section{Capturing the changes in Korea's road infrastructure}

The first step in gauging some of the outcomes of road infrastructure investment in Korea is the development of indicators that capture the difference in the road network. Korea has expanded its road structure continuously over the past decades. The length of total paved roads increased by more than $80 \%$ between 1992 and 2013 (Figure 1). The traffic volume, measured in terms of vehicle-kilometres travelled, has kept pace with the development, reflecting the increased demand for infrastructure. This match between infrastructure supply and demand is not always evident, a recent OECD survey for Japan (OECD, 2016b) highlights that the national network of trunk roads nearly tripled in length between 1986 and 2014, whereas the number of passenger-kilometres driven rose only by $3.2 \%$ and has remained largely constant since $1999 .^{2}$ 
Figure 1. Paved roads and vehicle-kilometres travelled, 1992-2013

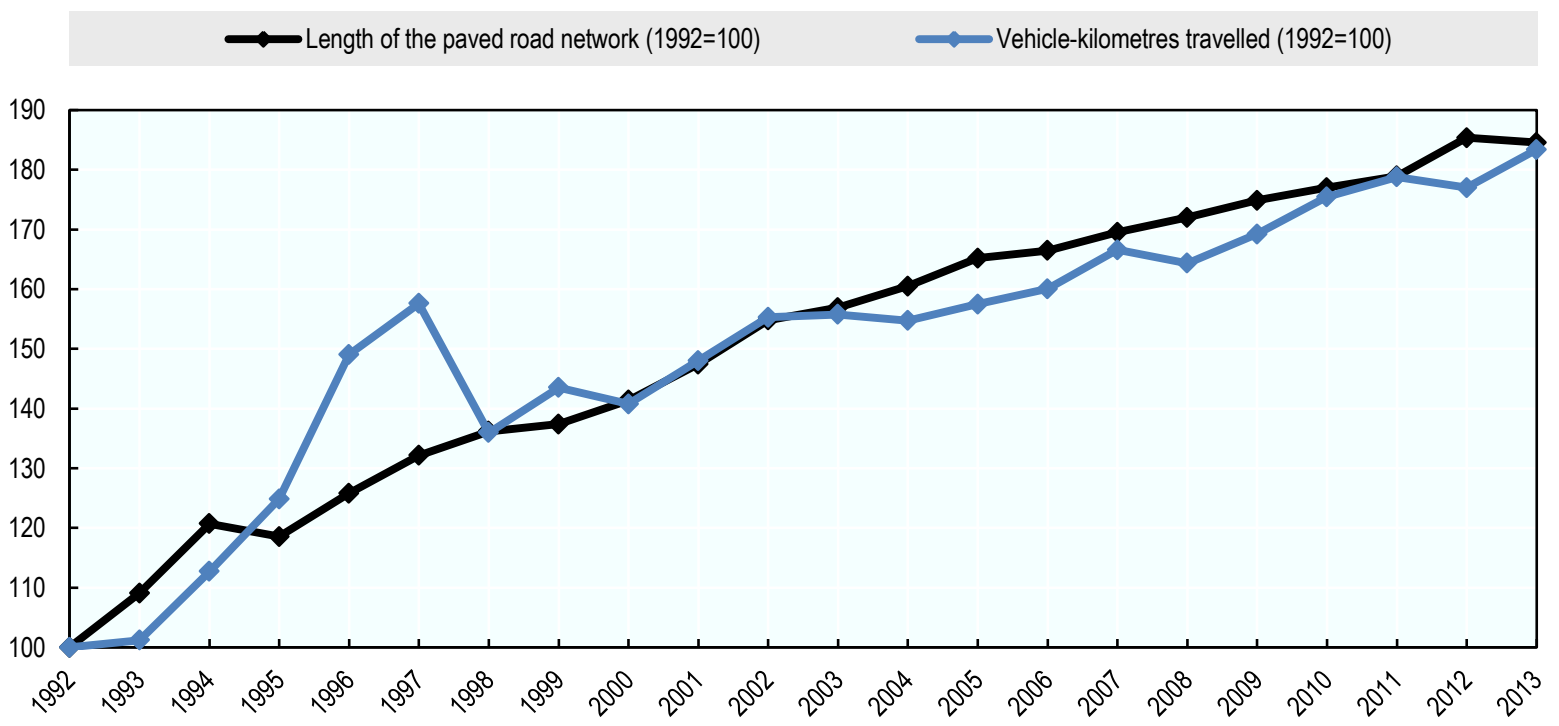

Source: OECD calculations based on MOLIT (2015), Road work manual [translated from Korean], Ministry of Land, Infrastructure and Transport, www.molit.go.kr/USR/BORD0201/m_34879/DTL.jsp?mode=view\&idx=30121 (accessed 20 August 2015) and KTDB (2015), "Vehicle-kilometres by road type" [translated from Korean], Korea Transport Database, The Korea Transport Institute, http://www.ktdb.go.kr/ko/web/guest/420 (accessed 30 November 2015).

\section{The expansion of Korea's network of major roads from 1992 to 2008}

The backbone of the road network in Korea consists of expressways, national highways and major local roads. The expressway network offers the fastest travel speeds, with allowed driving speeds of up to $120 \mathrm{~km} / \mathrm{h}$, while national highways and other major roads have speed limits of $80 \mathrm{~km} / \mathrm{h}$ or less. ${ }^{3}$ Figure 2 depicts the change in road infrastructure for these three types of roads between 1992 and 2008. New roads were developed in all parts of the country, with a concentration of new development around Seoul that spreads southwards in a triangle that covers the major Korean cities.

The expansion of the Korean expressway network is ongoing and constantly moving towards the $7 \mathrm{x} 9$ grid that was envisaged in the $3^{\text {rd }}$ Comprehensive National Transport Development Plan 1992-2001. Figure 3 shows the current state of the expressway network and the planned expansions until 2020. By 2013, the total paved road length exceeded 87000 kilometres, including more than 4100 kilometres of high speed expressways. Korea continues to invest in its road and rail infrastructure with a total budget of KRW 15.8 trillion (Korean Won) or 1.1\% of 2013 GDP. 
Figure 2. Expansion of Korea's Expressway network, 1992-2008
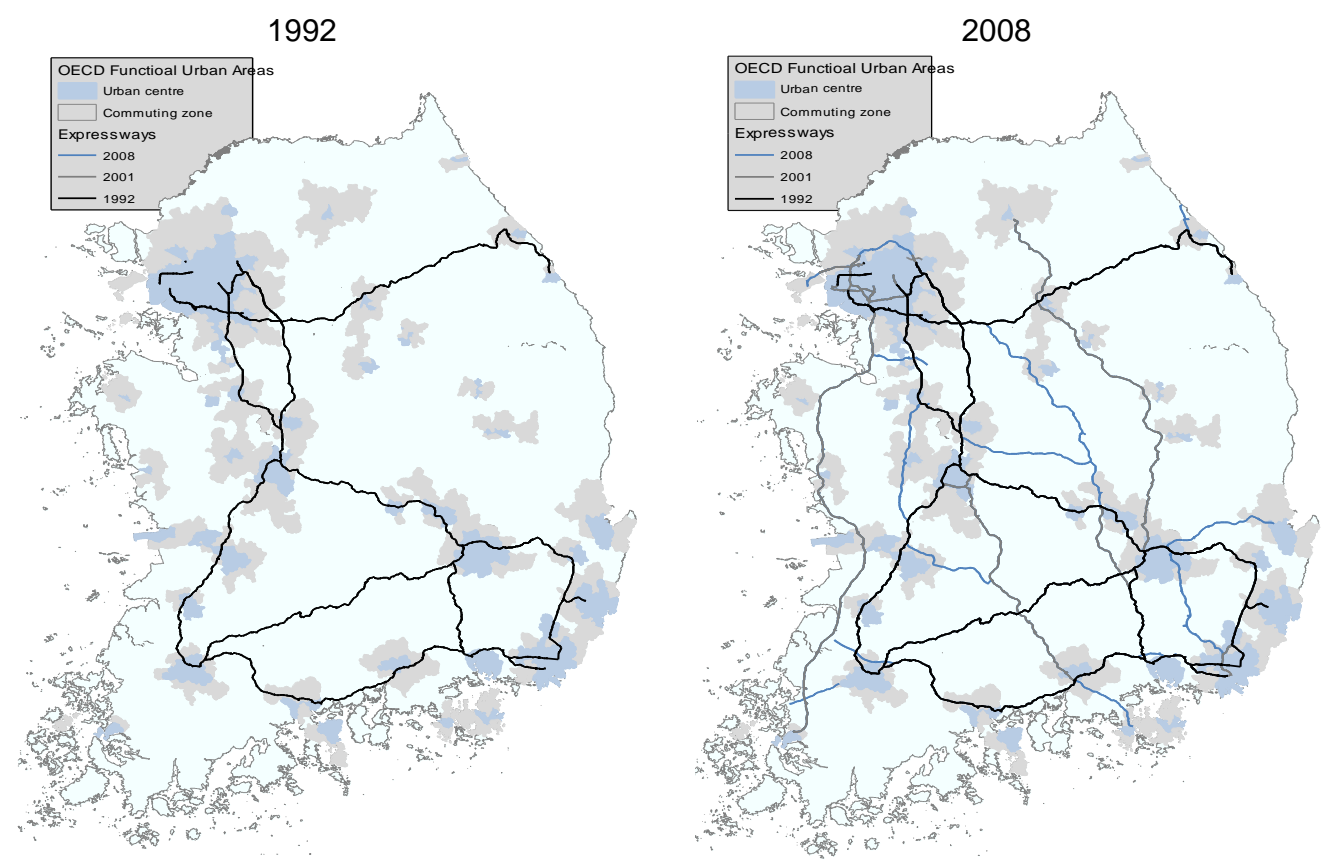

Source: Data and maps provided by MOLIT (unpublished).

Figure 3. Planned expansion of the Korean Expressway Network

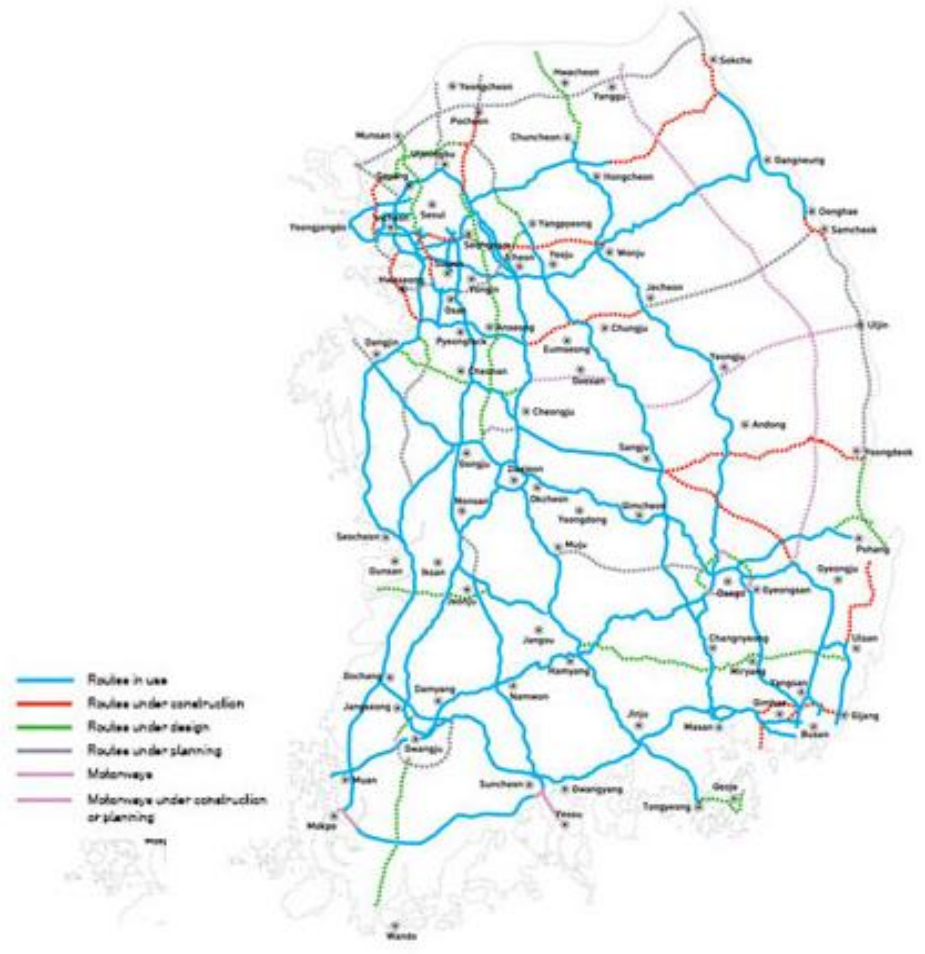

Source: Korea Expressway Corporation, available at http://www.ex.co.kr/images/site/portal/eng/domestic/map.jpg (accessed 2 September 2016). 


\section{(Market) access: Opportunities that can be reached by driving 60, 120 or 180 minutes}

The indicator that captures improvements in road infrastructure is the change in (market) access. This indicator aims to capture the opportunities for firms and residents within a reasonable driving distance. Three distance bands are considered, a drive of up to one hour, between one and two hours and a two to three hour drive. The first band covers most people's maximum daily commute, though in some places commutes in excess of one hour are not uncommon, e.g. in London more than $20 \%$ of the workforce commutes at least one hour. ${ }^{4}$ Among OECD countries, Korea's workforce spends, on average, the most time commuting, ${ }^{5}$ so even opportunities within the area that can be accessed within 60-120 minutes of driving may fall within the potential commute. For the most part, opportunities within 60-120 and 120-180 minutes are those relevant for daytrips, either for leisure or for business purposes.

The indicator for (market) access is calculated using detailed digitised road maps for Korea and calculated for each city $(\mathrm{Si})$, county (Gun) and autonomous district $(\mathrm{Gu})$ - corresponding to the lower tier of Korea's two-tier system of local government or Territorial Level 4 (TL4) level in the OECD typology. To this end, each segment of the road network is assigned a driving speed. The segments are then aggregated until 60,120 or 180 minutes are reached. The resulting endpoints of all possible routes are connected to form the "catchment areas" for the different driving distances.

The indicator is constructed in three steps. First, as a starting point for the calculations, the population weighted centroid for each TL4 area is calculated. The resulting point indicates the expected location of a randomly chosen resident within the area. From this starting point, the area that can be covered within 60 , 120 and 180 minutes of driving is calculated. For the calculation of these "catchment" areas, the digitised network of expressways, highways and major local roads are used and maximum travel distance on each road segmented and calculated assuming an average speed ${ }^{6}$ of:

- $90 \mathrm{~km} / \mathrm{h}$ on expressways,

- $\quad 57 \mathrm{~km} / \mathrm{h}$ on national highways,

- $50 \mathrm{~km} / \mathrm{h}$ on major local roads.

To create a measure for the opportunities within the catchment area, the measure for (market) access aggregates the population living in each one square kilometre cell within the catchment area. Data on population comes from Landscan (2009). To avoid confounding cause and effect, the population used for the aggregation is fixed and does not change for different years. With data that is spatially sufficiently detailed, other indicators could be used to capture opportunities, e.g. the number of jobs or the number of cultural facilities within the area, but typically only population data is available at a sufficiently detailed scale. While a larger accessible consumer market, captured by the (market) access indicator, is not necessarily synonymous with access to jobs, goods or services, there is a strong correlation among these aspects and the (market) access indicator is interpreted more widely as proxy for access to opportunities.

Figure 4 depicts the change in catchment areas for Yecheon-gun, a county for which accessibility strongly increased following the creation of two major expressways. While it took more than three hours in 1992 to reach Seoul or Busan, the two largest cities in Korea, both cities could be accessed in three hours or less by 2008. To capture the benefit of this increase in accessibility, (market) access is calculated by summing up the number of people living within the catchment area. 


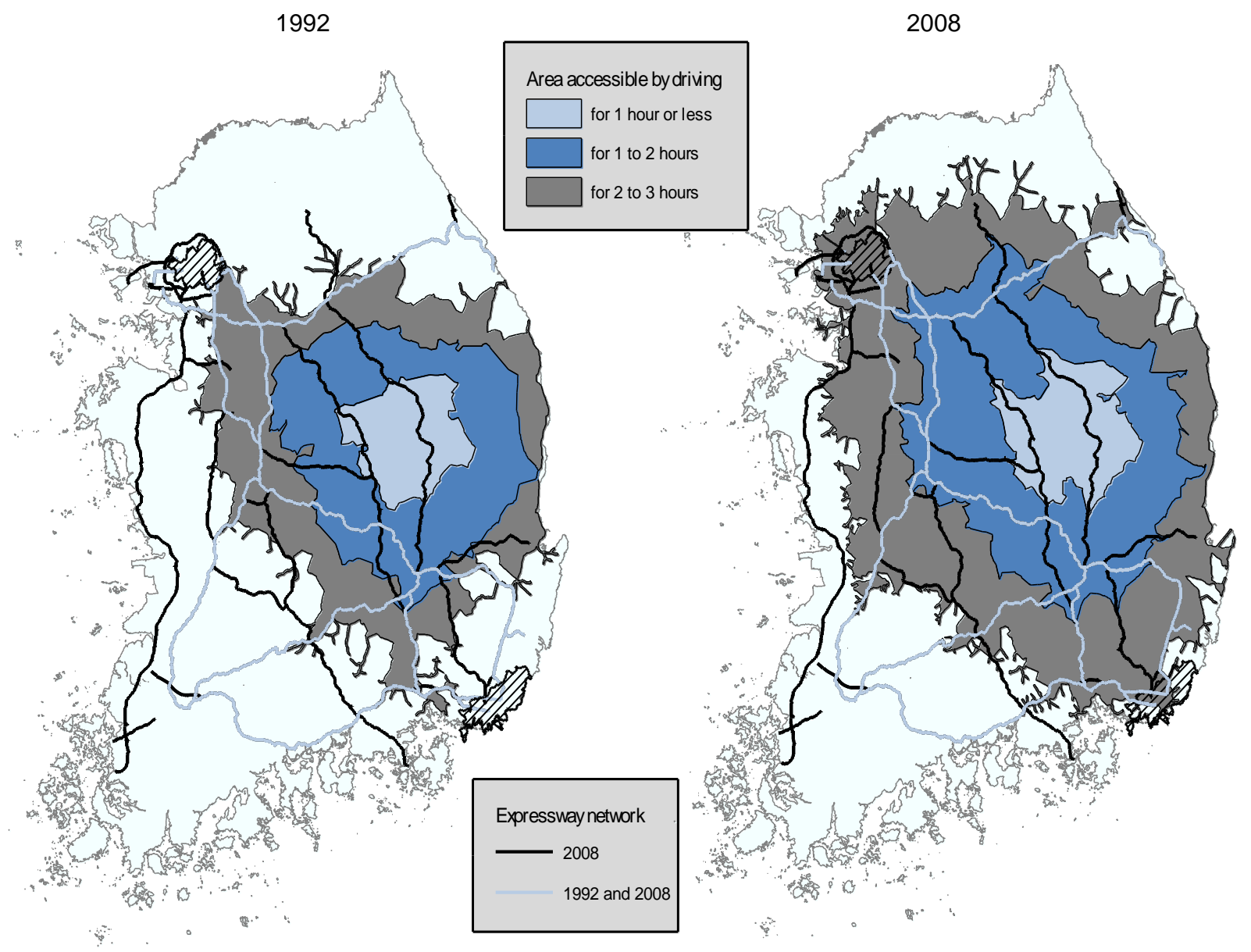

Note: The cities of Seoul and Busan are shown as hatched areas in the north-east and south-west respectively.

Source: Authors' calculations based on Landscan (2009) and road maps provided by MOLIT (unpublished).

\section{Estimating the impact of improved (market) access on incumbent firms in Korea}

This study focuses on incumbent firms to highlight one specific channel of how improved accessibility affects firms. On the one hand, the focus is due to the limitation of the available data. The ORBIS database, described in the following, is not well suited to model the entry and exit of firms. On the other hand, there are also theoretical and empirical reasons why a separate treatment of incumbent firms is warranted. International evidence suggests that incumbent and new firms differ in their capacity to leverage opportunities created by improved infrastructure. For the UK, for example, estimates show that incumbent firms do not benefit from increased accessibility, but that positive effects on employment are driven by new firms entering the market (Gibbons et al., 2012). Complementing the evidence on employment, Sanchis-Guarner (2014) finds that employees' earnings increase with increasing (market) access. Her results suggest that earnings increase through two channels. The first is workers with higher wages choosing to live in more accessible locations. The second, arguably more important, channel is driven by firms being more accessible to workers. Both earnings and hours worked of employees increase, in line with positive agglomeration economies. Evidence from Spain highlights the importance of distinguishing between manufacturing and service sector firms. Holl (2014) finds 
that small manufacturing firms in urban areas are particularly able to capture gains in productivity from increased connectivity.

\section{Data on Korean firms}

Firm-level variables come from the ORBIS database. ORBIS, provided by the Bureau Van Dijk, includes balance-sheet information for over 100 million companies around the globe. Along with many advantages, this commercial dataset also carries a number of caveats. First, there is evidence that ORBIS is not necessarily representative of the underlying business population within a country, and that coverage varies over countries and time without any clear patterns (see for example Bravo-Biosca et al., 2013). In particular, young and small firms tend to be systematically underrepresented in most countries. For Korea, a comparison of employment from the nationally-representative "OECD Structural Analysis Database (STAN), derived from National Accounts, and the ORBIS database shows that the overall coverage, about 1 in 12 employees, is better than the average coverage for OECD countries. But for small firms (1-9 employees), coverage is only about average with 1 in 36 employees (Gal, 2013). This might introduce a selection bias in the estimates if not adequately accounted for in the estimation strategy.

The required assumption for the estimates to be unaffected by selection bias is that future changes in accessibility do not affect the probability of being selected into the sample, conditional on firm fixed effects and all other fixed effects included in the regressions. There is no direct way to test this assumption, but it appears reasonably plausible. Information on firms' accounts from ORBIS typically starts in 1998, but coverage increases significantly since 2001; the analysis therefore starts in that year. The last year covered is 2014. In order to avoid double counting, balance sheet information from ORBIS is restricted to unconsolidated accounts, which are also typically the only available option for Korea. ${ }^{7}$ To match the ORBIS firms to the area they are located in, zip codes in the ORBIS data were matched using the mapping of zip codes to geographical latitude and longitude commercially provided by mapanet.eu. The outcomes considered in this study are employment, total sales, the firm's value added, employee wages, value of fixed assets, labour productivity, and multi-factor productivity (MFP). For MFP, the work adopts the estimation of Gal (2013) and uses as the main TFP variable the metrics develop by Wooldridge (2009). 
Table 1. Descriptive statistics for the manufacturing and service samples

\begin{tabular}{|c|c|c|c|c|c|c|}
\hline & $\begin{array}{l}\text { Employment } \\
\text { (In) }\end{array}$ & $\begin{array}{l}\text { Wage bill } \\
\text { (In) }\end{array}$ & $\begin{array}{c}\text { Gross } \\
\text { output (In) }\end{array}$ & $\begin{array}{c}\text { Fixed } \\
\text { assets (In) }\end{array}$ & $\begin{array}{l}\text { Labour } \\
\text { productivit } \\
\text { y (In) }\end{array}$ & MFP \\
\hline \multicolumn{7}{|c|}{ Panel A: Manufacturing } \\
\hline Observations & 399577 & 377330 & 399577 & 398765 & 399577 & 289500 \\
\hline Average & 2.9 & 8.8 & 14.8 & 13.6 & 11.8 & 0.7 \\
\hline $\begin{array}{l}\text { Standard } \\
\text { deviation }\end{array}$ & 1.3 & 1.1 & 1.7 & 2.1 & 1.0 & 1.9 \\
\hline First quartile & 2.1 & 8.3 & 13.7 & 12.2 & 11.3 & -0.2 \\
\hline Median & 2.8 & 9.0 & 14.7 & 13.6 & 11.8 & 0.8 \\
\hline Third quartile & 3.8 & 9.5 & 15.8 & 14.9 & 12.4 & 1.8 \\
\hline \multicolumn{7}{|c|}{ Panel B: Services } \\
\hline Observations & 581970 & 564886 & 581970 & 577550 & 581970 & 297080 \\
\hline Average & 2.3 & 9.5 & 14.3 & 12.4 & 11.9 & 3.9 \\
\hline $\begin{array}{l}\text { Standard } \\
\text { deviation }\end{array}$ & 1.3 & 1.1 & 1.7 & 2.1 & 1.4 & 2.1 \\
\hline First quartile & 1.4 & 8.9 & 13.2 & 11.0 & 11.0 & 2.3 \\
\hline Median & 2.2 & 9.6 & 14.2 & 12.2 & 12.0 & 4.4 \\
\hline Third quartile & 3.0 & 10.2 & 15.3 & 13.6 & 12.8 & 5.0 \\
\hline
\end{tabular}

\begin{tabular}{|c|c|c|c|}
\hline & $\begin{array}{l}\text { 0-60 min accessibility } \\
\text { (In) }\end{array}$ & $\begin{array}{l}\text { 60-120 min accessibility } \\
\text { (In) }\end{array}$ & $\begin{array}{l}120-180 \mathrm{~min} \\
\text { accessibility (In) }\end{array}$ \\
\hline \multicolumn{4}{|c|}{ Panel A: Manufacturing } \\
\hline Observations & 397940 & 397940 & 397940 \\
\hline Average & 15.8 & 15.8 & 15.5 \\
\hline Standard deviation & 1.1 & 0.5 & 0.5 \\
\hline First quartile & 15.1 & 15.5 & 15.2 \\
\hline Median & 15.7 & 15.6 & 15.3 \\
\hline Third quartile & 16.9 & 15.8 & 15.8 \\
\hline \multicolumn{4}{|c|}{ Panel B: Services } \\
\hline Observations & 573784 & 564886 & 581970 \\
\hline Average & 15.9 & 9.5 & 14.3 \\
\hline Standard deviation & 1.3 & 1.1 & 1.7 \\
\hline First quartile & 15.0 & 8.9 & 13.2 \\
\hline Median & 16.8 & 9.6 & 14.2 \\
\hline Third quartile & 16.9 & 10.2 & 15.3 \\
\hline
\end{tabular}

Source: Authors' elaborations based on BvD-ORBIS data. 


\section{Empirical specification}

The empirical analysis relies on panel fixed-effect regressions to establish a link between the changes in road infrastructure and relevant outcomes at firm level. The underlying model is non-linear and becomes linear when taking natural logarithms. The use of the natural logarithm is common in the literature on the impact of transport infrastructure on regions (e.g. Michaels, 2008) or firms (Gibbons et al., 2012) and arises naturally in different economic models, e.g. in the monocentric city model with quasilinear utility (Baum-Snow, 2007). The logarithmic formulation allows to flexibly capture returns to scale, e.g. increasing the number of potential workers from 100000 to 200000 is likely to have a different impact on firms than increasing the number from 15 million to 15.1 million. The model used in this study allows for such a differential impact. The first baseline model estimates the change in outcomes that accompanies the investment in road infrastructure across all firms. Specifically, the model takes the following form:

$$
y_{i t}=\beta_{0}+\beta_{1} X_{i t}+\gamma_{i}+\gamma_{t}+\varepsilon_{i t}
$$

The variable $y_{i t}$ is the outcome of interest. In the model, the regressor of interest is captured in the vector $X_{i t}$, which is linearly interpolated for years in which no map was available. The baseline model is estimated separately for manufacturing and service sector firms. In addition to the main regressor(s), the model accounts for firm and time fixed effects $\left(\gamma_{i}\right.$ and $\left.\gamma_{t}\right)$. These fixed effects capture any characteristic of a firm that is fixed over time (e.g. firms that are better managed as opposed to those that have worse management) or factors that increase by the same margin for all firms (e.g. the age of a firm - an important characteristic in many studies of firm outcomes $\left.{ }^{8}\right) \cdot \varepsilon_{i t}$ denotes an error term assumed to be independently and identically distributed. Standard errors are clustered at the Si-Gun-Gu level. Since all continuous variables enter the equation in logarithmic form (e.g. $\left.y_{i t}\right)$, coefficients can be interpreted as elasticities.

The dependent variables are the following six measures of firm size, input, output, and performance: employment; wage bill; gross output; fixed assets; labour productivity (gross output per employee); multifactor productivity (estimated with the methodology developed by Wooldridge, 2009; see also Gal, 2013, for a discussion of the implementation of the methodology on ORBIS data).

Given the difference in tradability of the output, studies typically find that firm in manufacturing and services are differently affected by transport improvements. Data availability often differs for firms in the two sectors, which makes a separate treatment appropriate. The model is therefore estimated separately on the two samples.

In addition to the baseline specification the study considers an extension that allows for a heterogeneous impact of transport infrastructure. In particular, it considers whether accessibility affected firms that are operating in low-tech manufacturing differently than firms that are manufacturers of medium-low or medium-high/high-tech goods. However, the classification into technological intensity is coarse, as it is based on industry-aggregate patterns. The study therefore uses the available estimates for multi-factor productivity to identify also the productivity "frontier" in manufacturing. The "frontier" is composed of those firms that are in the top $10 \%$ of the estimated multi-factor productivity distribution in each year. ${ }^{9}$ The heterogeneous impact is introduced by including an interaction between accessibility and a vector of dummy variables for three technological-intensity classes or dummies distinguishing between frontier and non-frontier firms $\left(\gamma_{c}\right)$.

$$
\ln \left(y_{i t}\right)=\beta_{0}+\beta_{1} X_{i t} * \gamma_{c}+\gamma_{i}+\gamma_{c t}+\varepsilon_{i t}
$$

In addition to the interaction with the dummy variable vector, the extended specification includes time fixed effects for each of the different classes considered $\left(\gamma_{c t}\right)$. This avoids confounding spurious common trends that depend on e.g. the technological intensity with accessibility improvements. A spurious positive 
impact of accessibility on firm outcomes could arise if, for example, high-tech firms become better connected and at the same time global demand for Korean high-tech products grows. Including the technology (or productivity)-specific time fixed effects $\gamma_{c t}$ controls for common demand factors within the classification and therefore eliminates the confounding factor.

A more detailed note on the role of fixed effects is in order. The fixed effect based empirical strategy allows to "partial out" several important confounding factors from the estimation. The baseline estimates capture the impact of road infrastructure on different outcomes conditional on cross-sectional and time fixed effects. Cross-sectional fixed effects rule out confounding factors which are unique to the firms and that remain constant during the period studied, including any first-geography components (e.g. the historical presence of airports or a railway lines, natural resources, the local climate, etc). Time fixed effects account for any trends that are common for all firms or regions across Korea (e.g. global trends, the business cycle, exchange rates, inflation, a general rise of motorisation across Korea, etc.). This only leaves sources for bias that satisfy two conditions: first the confounding factors need to simultaneously change in time and across firms; second, the confounding factors need to be correlated with changes in the available road infrastructure. Importantly, these changes need to be relevant at the country-wide level, i.e. if in a region a rail station was established alongside significant road investments, the bias would be negligible. The creation of new rail stops only confounds the analysis if it is a general pattern with significant correlation.

Despite the richness of the fixed effect specification, the inclusion of additional controls might seem attractive. In this study the exclusion of additional controls is however deliberate. The view taken in this study is that most firm-level characteristics are themselves outcomes that dependent on accessibility. E.g. improved accessibility changes not only size of the market in which firms can sell their goods, but also the number and type of workers that live within commuting distance, potentially affecting employment, skill-intensity, the wage bill, capital stock, etc. They are therefore "bad" controls in the terminology of Angrist and Pischke (2009) and should not be included on the right hand side of the above equations.

Despite the ability to control for a rich set of confounding factors, a final word of caution is in order with respect to the causal interpretation of the results. For sake of expositional simplicity the results are interpreted as estimations of causal links. There remains, however the possibility that the geography of the development of the expressway network may be partly endogenous with respect to local firm performance as the selection might arise through some time-varying factors. For instance, if the decision on where and when the expressway network is expanded is taken based on recent changes in local firm performance, e.g. to support growing firms or help to stop a trend of firms declining, the estimates would not report the true causal effect, but rather some robust partial correlation. This caveat has to be kept in mind when interpreting the econometric results.

\section{Empirical results}

The baseline results reported in Table 2 show the impact of an increase in accessibility in an area that can be reached within three hours of driving. This pools a variety of aspects that might improve firm outcomes, ranging from widening the market for a firm's sales over an increase in competition to an increase in the labour pool available within commuting distance. For manufacturing firms this wide-ranging increase in accessibility is associated positively with outcomes on total employment, wages and gross output, as well as on labour productivity. While improvements in accessibility do not increase these outcomes in a statistical sense, there is also no evidence for a negative impact or displacement of activity. For incumbent firms in the manufacturing sector, only fixed assets, i.e. the value of assets such as machinery, vehicles, land or office equipment owned by the firm, and multi-factor productivity (MFP), a measure of how efficiently a firm combines capital and labour into output, are negatively and statistically 
significantly affected. Importantly, neither the reduction of the value of fixed assets nor of multi-factor productivity translates into a decline in output.

For service sector firms the same baseline regressions also show no significant impact on gross output. Service firms do, however, seem to reduce employment: a 10\% increase accessibility (i.e. increasing the number of people that can be reached within three hour of driving by $10 \%$ ) is, on average, associated with $2 \%$ decline in firm-level employment. This decline is mirrored by a corresponding increase in labour productivity, indicating that firms reduce their activity in low-productivity aspects of their service delivery. The increase in labour productivity is also reflected in an increase in multi-factor productivity, albeit at a smaller scale with $1 \%$ increase associated with a $10 \%$ increase in accessibility. It is worth noting, that productivity estimates for the service sectors pose a number of additional methodological challenges. The estimation of multi-factor productivity relies on firms' demand for intermediate inputs and the built-up of fixed assets. In service sectors both of these factors tend to differ substantially compared to manufacturing firms. MFP results for service sector firms should therefore be interpreted with caution. Despite the difficulty in comparing fixed assets between manufacturing and service sector firms, the statistically significant and negative relationship of fixed assets associated with an increase in accessibility is also present for service sector firms.

Table 2. Accessibility improvements within 0-180 minutes driving

\begin{tabular}{|c|c|c|c|c|c|c|}
\hline & Employment & Wage bill & Gross output & Fixed assets & Labour prod. & MFP \\
\hline \multicolumn{7}{|c|}{ Panel A: Manufacturing } \\
\hline $0-180 \mathrm{~min}$ & 0.029 & 0.119 & 0.201 & $-0.707^{\star \star \star}$ & 0.171 & $-0.094^{* *}$ \\
\hline accessibility (In) & $(0.083)$ & $(0.096)$ & $(0.156)$ & $(0.180)$ & $(0.115)$ & $(0.044)$ \\
\hline Observations & 397735 & 373368 & 397735 & 396782 & 397735 & 275646 \\
\hline R-squared & 0.932 & 0.804 & 0.913 & 0.924 & 0.764 & 0.993 \\
\hline Fixed effects & Firm; year & Firm; year & Firm; year & Firm; year & Firm; year & Firm; year \\
\hline \multicolumn{7}{|c|}{ Panel A: Manufacturing } \\
\hline $0-180 \mathrm{~min}$ & $-0.197^{\star \star}$ & 0.102 & -0.007 & $-0.552^{\star \star \star}$ & $0.190^{*}$ & $0.105^{\star *}$ \\
\hline accessibility (In) & $(0.078)$ & $(0.079)$ & $(0.128)$ & $(0.174)$ & $(0.106)$ & $(0.049)$ \\
\hline Observations & 573524 & 554768 & 573524 & 568612 & 573524 & 271602 \\
\hline R-squared & 0.926 & 0.795 & 0.878 & 0.925 & 0.823 & 0.989 \\
\hline Fixed effects & Firm; year & Firm; year & Firm; year & Firm; year & Firm; year & Firm; year \\
\hline
\end{tabular}

Note: Firm-level panel fixed effect estimations. Standard errors clustered at the Si-Gun-Gu level in parenthesis. See text for data description and details on the empirical strategy. All variables are expressed in natural logarithms.

Source: Authors' elaborations based on BvD ORBIS data.

The combined effect of improved accessibility for short and long distance trips captures the aggregate effect of accessibility improvements on firm outcomes. But improving local accessibility (within one hour of driving) is likely to have different impacts that arise through different mechanisms than an increase in accessibility within a two to three hour drive. Local accessibility is more relevant for the commuting zone of employees and locally provided services, whereas longer distances are more relevant for infrequent business trips. What constitutes "local" is of course not fixed; some people might be willing to spend more time commuting than others. In Korea, where commutes are relatively long, this means that part of the intermediate band - one to two hour driving accessibility - might also be, at least in part, a wider commuting zone. 
Splitting improvements in accessibility for short (0-60 minutes), intermediate (60-120 minutes) and long distances (120-180 minutes) shows that the impact is indeed heterogeneous. This is less the case for manufacturing firms, where only the impact of accessibility on wages is affected by the distance bands considered. More variation arises for service sector firms. The relationship of accessibility and employment, adjustments in fixed assets and multi-factor productivity differs depending on whether local or long-distance accessibility improves. For service firms employment increases if local accessibility improves and this increase in employment is accompanied by rising MFP. Conversely service sector firms that experience accessibility improvements at long distances reduced, on average, their workforce and their fixed assets.

Table 3. Accessibility improvements in distance bands, 0-60; 60-120 and 120-180 minutes driving

\begin{tabular}{|c|c|c|c|c|c|c|}
\hline & Employment & Wage bill & $\begin{array}{l}\text { Gross } \\
\text { output }\end{array}$ & Fixed assets & $\begin{array}{l}\text { Labour } \\
\text { prod. }\end{array}$ & MFP \\
\hline \multicolumn{7}{|c|}{ Panel A: Manufacturing } \\
\hline $0-180 \mathrm{~min}$ & 0.022 & -0.058 & -0.015 & $-0.179^{\star \star}$ & -0.037 & -0.032 \\
\hline accessibility (In) & $(0.052)$ & $(0.078)$ & $(0.074)$ & $(0.083)$ & $(0.038)$ & $(0.025)$ \\
\hline $60-120 \mathrm{~min}$ & -0.016 & -0.087 & -0.027 & $-0.340^{\star \star}$ & -0.011 & $-0.050^{*}$ \\
\hline accessibility (In) & $(0.048)$ & $(0.055)$ & $(0.081)$ & $(0.133)$ & $(0.049)$ & $(0.027)$ \\
\hline $120-180 \mathrm{~min}$ & -0.040 & $0.083^{\star *}$ & 0.0029 & $-0.257^{\star * *}$ & 0.043 & -0.020 \\
\hline accessibility (In) & $(0.038)$ & $(0.039)$ & $(0.064)$ & $(0.092)$ & $(0.039)$ & $(0.016)$ \\
\hline Observations & 397735 & 373368 & 397735 & 396782 & 397735 & 275646 \\
\hline R-squared & 0.932 & 0.804 & 0.913 & 0.924 & 0.764 & 0.993 \\
\hline Fixed effects & Firm; year & Firm; year & Firm; year & Firm; year & Firm; year & Firm; year \\
\hline \multicolumn{7}{|c|}{ Panel B: Services } \\
\hline $0-60 \mathrm{~min}$ & $0.095^{\star *}$ & -0.049 & 0.025 & -0.049 & -0.069 & $0.051^{* *}$ \\
\hline accessibility (In) & $(0.045)$ & $(0.050)$ & $(0.073)$ & $(0.105)$ & $(0.053)$ & $(0.024)$ \\
\hline $60-120 \mathrm{~min}$ & 0.042 & -0.063 & 0.042 & -0.023 & -0.0004 & -0.024 \\
\hline accessibility (In) & $(0.062)$ & $(0.049)$ & $(0.081)$ & $(0.145)$ & $(0.050)$ & $(0.028)$ \\
\hline $120-180 \mathrm{~min}$ & $-0.122^{\star \star \star}$ & -0.014 & -0.099 & $-0.296^{\star \star *}$ & 0.023 & -0.023 \\
\hline accessibility (In) & $(0.047)$ & $(0.052)$ & $(0.060)$ & $(0.110)$ & $(0.046)$ & $(0.022)$ \\
\hline Observations & 573524 & 554768 & 573524 & 568612 & 573524 & 271602 \\
\hline R-squared & 0.926 & 0.795 & 0.878 & 0.925 & 0.823 & 0.989 \\
\hline Fixed effects & Firm; year & Firm; year & Firm; year & Firm; year & Firm; year & Firm; year \\
\hline
\end{tabular}

Note: Firm-level panel fixed effect estimations. Standard errors clustered at the Si-Gun-Gu level in parenthesis. See text for data description and details on the empirical strategy.

Source: Authors' elaborations based on BvD ORBIS data.

While improvements in accessibility open up new opportunities for firms, these opportunities are also likely to attract new firms or new residents. This means that costs for land and building rents are likely to rise. Cervero and Kang (2011), for example, find that land prices rose in areas around bus stops when Seoul's bus rapid transit system was introduced. These changes might be particularly relevant for incumbent firms. They chose to locate in an area that was less accessible to begin with and might have preferred to retain lower levels of accessibility but also lower land prices. This is particularly the case for firms in regions with high transport costs, which insulates these firms from competition in their local market. Fiercer competition ensures that unproductive businesses innovate and improve or leave the market, which creates aggregate benefits but not necessarily for the incumbent firm. 
The benefits of improved accessibility are likely stronger for firms that require highly skilled or specialised workers than for firms with a workforce that relies on basic skills. ${ }^{10}$ The former are typically competing through innovation or by developing leadership in niches, while the latter typically compete on costs and even moderate changes in their input costs might strongly affect their profit margins. While the data does not offer a perfect measure to capture these possible channels, it allows to consider the technology-intensity of manufacturing firms. In Table 4, firms are classified into low-tech ("lowtech"), medium-low tech ("medtech") and medium-high/high-tech ("hightech") and the impact of accessibility is allowed to vary with technological intensity (see Table A.1. in the Annex for the list of sectors and their classification).

The results show some heterogeneity in the degree to which change in accessibility is associated with firm inputs. In particular, how labour and fixed assets change differs across firms in different technological intensity classes. As surmised above, low-tech firms tend to reduce employment when accessibility increases. The effect is stronger for intermediate and long distances, pointing towards competition among firms as a possible channel. For medium-low tech firms, the opposite is the case. For them, increased accessibility in the local and intermediate range is positively associated with employment, albeit not always statistically significantly. A recurring result is that the value of fixed assets declines as accessibility improves. In the breakdown by technological intensity this effect is stronger at the lower and upper end of the spectrum.

Table 4. Accessibility improvements in distance bands, 0-60; 60-120 and 120-180 minutes driving and technological intensity

\begin{tabular}{|c|c|c|c|c|c|c|}
\hline & Employment & Wage bill & Gross output & Fixed assets & Labour prod. & MFP \\
\hline \multirow{2}{*}{$\begin{array}{l}\text { lowtech\# } \\
0-60 \text { min }\end{array}$} & -0.007 & -0.014 & -0.018 & $-0.185^{\star *}$ & -0.011 & -0.007 \\
\hline & $(0.056)$ & $(0.076)$ & $(0.074)$ & $(0.087)$ & $(0.037)$ & $(0.022)$ \\
\hline \multirow{2}{*}{$\begin{array}{l}\text { medtech\# } \\
0-60 \text { min }\end{array}$} & $0.148^{*}$ & -0.078 & 0.107 & 0.143 & -0.042 & -0.002 \\
\hline & $(0.086)$ & $(0.104)$ & $(0.130)$ & $(0.145)$ & $(0.061)$ & $(0.028)$ \\
\hline \multirow{2}{*}{$\begin{array}{l}\text { hightech\# } \\
0-60 \text { min }\end{array}$} & 0.046 & -0.114 & 0.0216 & $-0.179^{*}$ & -0.025 & -0.034 \\
\hline & $(0.050)$ & $(0.088)$ & $(0.078)$ & $(0.097)$ & $(0.048)$ & $(0.051)$ \\
\hline \multirow{2}{*}{$\begin{array}{l}\text { lowtech\# } \\
60-120 \text { min }\end{array}$} & $-0.143^{\star *}$ & 0.006 & -0.091 & $-0.455^{\star \star \star}$ & 0.051 & 0.018 \\
\hline & $(0.057)$ & $(0.068)$ & $(0.075)$ & $(0.121)$ & $(0.044)$ & $(0.021)$ \\
\hline \multirow{2}{*}{$\begin{array}{l}\text { medtech\# } \\
60-120 \text { min }\end{array}$} & 0.033 & -0.125 & -0.039 & -0.341 & -0.072 & -0.030 \\
\hline & $(0.107)$ & $(0.090)$ & $(0.157)$ & $(0.213)$ & $(0.080)$ & $(0.044)$ \\
\hline \multirow{2}{*}{$\begin{array}{l}\text { hightech\# } \\
60-120 \mathrm{~min}\end{array}$} & $0.097^{*}$ & $-0.194^{* * *}$ & 0.067 & -0.227 & -0.030 & $-0.117^{\star *}$ \\
\hline & $(0.058)$ & $(0.055)$ & $(0.094)$ & $(0.151)$ & $(0.061)$ & $(0.054)$ \\
\hline \multirow{2}{*}{$\begin{array}{l}\text { lowtech\# } \\
120-180 \text { min }\end{array}$} & $-0.086^{\star \star}$ & 0.082 & -0.025 & $-0.317^{\star \star \star}$ & 0.061 & 0.005 \\
\hline & $(0.042)$ & $(0.052)$ & $(0.061)$ & $(0.082)$ & $(0.042)$ & $(0.021)$ \\
\hline \multirow{2}{*}{$\begin{array}{l}\text { medtech\# } \\
120-180 \text { min }\end{array}$} & 0.088 & 0.045 & 0.128 & -0.0008 & 0.040 & $-0.065^{\star \star}$ \\
\hline & $(0.079)$ & $(0.069)$ & $(0.114)$ & $(0.159)$ & $(0.073)$ & $(0.030)$ \\
\hline \multirow{2}{*}{$\begin{array}{l}\text { hightech\# } \\
120-180 \text { min }\end{array}$} & -0.040 & $0.089^{* *}$ & 0.016 & $-0.274^{* *}$ & 0.056 & -0.028 \\
\hline & $(0.052)$ & $(0.037)$ & $(0.086)$ & $(0.106)$ & $(0.054)$ & $(0.027)$ \\
\hline Observations & 387445 & 363635 & 387445 & 386571 & 387445 & 268451 \\
\hline R-squared & 0.932 & 0.804 & 0.914 & 0.924 & 0.763 & 0.993 \\
\hline Fixed effects & $\begin{array}{c}\text { Firm; } \\
\text { year\#tech. }\end{array}$ & $\begin{array}{l}\text { Firm; } \\
\text { year\#tech. }\end{array}$ & $\begin{array}{l}\text { Firm; } \\
\text { year\#tech. }\end{array}$ & $\begin{array}{l}\text { Firm; } \\
\text { year\#tech. }\end{array}$ & $\begin{array}{l}\text { Firm; } \\
\text { year\#tech. }\end{array}$ & $\begin{array}{l}\text { Firm; } \\
\text { year\#tech. }\end{array}$ \\
\hline
\end{tabular}

Note: Firm-level panel fixed effect estimations including year fixed effects for each of the three technology classes. A \# indicates an interaction term. Standard errors clustered at the Si-Gun-Gu level in parenthesis. See text for data description and details on the empirical strategy.

Source: Authors' elaborations based on BvD ORBIS data. 
Technological intensity is a useful, but rather coarse measure for the capacity of a firm to make use of opportunities provided by new infrastructure. An alternative is to utilise the available data to identify the most productive firms in a given year. These "frontier" firms show the capacity to use their inputs more effectively and efficiently than their competitors. If this capacity arises from better, more innovative and dynamic management, this might also translate into the ability to develop new processes or even products that make use accessibility improvements. In Table 5, accessibility indicators are interacted with a dummy variable that indicates whether a firm belongs to the $10 \%$ most productive (in terms of MFP) firms within the same 2-digit sector. As mentioned above, the calculation of MFP for service sector firms is less reliable than for manufacturing firms and Table 5 therefore excludes, again, the service sector.

The results do suggest that frontier firms are indeed better able to internalise benefits. Gross output increases in frontier firms when local accessibility improves. It is important to note that among all specifications considered, this is the only statistically significant effect on output. The increase comes in part from an increase in the number of workers in the firms, and in part from increased labour productivity. Frontier firms that experienced accessibility increases at intermediate driving distances showed a different response. For these firms labour productivity also increased, but was accompanied by downsizing and wage increases. This pattern is in line with skill-upgrading in the workforce and a move from labour-intensive to skill-intensive production.

Table 5. Accessibility improvements in distance bands, 0-60; 60-120 and 120-180 minutes driving and the productivity frontier

\begin{tabular}{|c|c|c|c|c|c|c|}
\hline & Employment & Wage bill & Gross output & Fixed assets & Labour prod. & MFP \\
\hline \multirow{2}{*}{$\begin{array}{l}\text { Bottom } 90 \% \\
\text { TFP\# 0-60 min }\end{array}$} & 0.015 & -0.063 & -0.039 & $-0.184^{\star *}$ & -0.054 & -0.043 \\
\hline & $(0.054)$ & $(0.083)$ & $(0.077)$ & $(0.087)$ & $(0.039)$ & $(0.026)$ \\
\hline \multirow{2}{*}{$\begin{array}{l}\text { Top 10\% TFP\# } \\
0-60 \mathrm{~min}\end{array}$} & 0.115 & -0.014 & $0.254^{\star *}$ & -0.067 & 0.139 & 0.006 \\
\hline & $(0.109)$ & $(0.109)$ & $(0.114)$ & $(0.134)$ & $(0.096)$ & $(0.032)$ \\
\hline \multirow{2}{*}{$\begin{array}{l}\text { Bottom } 90 \% \\
\text { TFP\# } 60-120 \\
\text { min }\end{array}$} & 0.007 & $-0.120^{\star *}$ & -0.021 & $-0.341^{* *}$ & -0.028 & $-0.064^{* *}$ \\
\hline & $(0.051)$ & $(0.056)$ & $(0.085)$ & $(0.140)$ & $(0.050)$ & $(0.026)$ \\
\hline \multirow{2}{*}{$\begin{array}{l}\text { Top } 10 \% \text { TFP\# } \\
60-120 \mathrm{~min}\end{array}$} & $-0.328^{* *}$ & $0.402^{* *}$ & -0.106 & -0.220 & $0.222^{\star *}$ & -0.000 \\
\hline & $(0.163)$ & $(0.155)$ & $(0.145)$ & $(0.201)$ & $(0.103)$ & $(0.041)$ \\
\hline \multirow{2}{*}{$\begin{array}{l}\text { Bottom } 90 \% \\
\text { TFP\# 120-180 } \\
\text { min }\end{array}$} & -0.030 & $0.076^{\star *}$ & 0.007 & $-0.258^{* * *}$ & 0.037 & -0.019 \\
\hline & $(0.040)$ & $(0.038)$ & $(0.064)$ & $(0.095)$ & $(0.040)$ & $(0.015)$ \\
\hline \multirow{2}{*}{$\begin{array}{l}\text { Top } 10 \% \text { TFP\# } \\
120-180 \mathrm{~min}\end{array}$} & -0.211 & 0.177 & -0.093 & $-0.283^{*}$ & 0.118 & 0.005 \\
\hline & $(0.133)$ & $(0.131)$ & $(0.130)$ & $(0.146)$ & $(0.109)$ & $(0.0387)$ \\
\hline Observations & 397735 & 373368 & 397735 & 396782 & 397735 & 275646 \\
\hline R-squared & 0.932 & 0.804 & 0.913 & 0.924 & 0.764 & 0.993 \\
\hline Fixed effects & $\begin{array}{c}\text { Firm; } \\
\text { Year\#TFPclas } \\
\text { s }\end{array}$ & $\begin{array}{c}\text { Firm; } \\
\text { Year\#TFPclas } \\
\text { s }\end{array}$ & $\begin{array}{c}\text { Firm; } \\
\text { Year\#TFPclas } \\
\text { s }\end{array}$ & $\begin{array}{c}\text { Firm; } \\
\text { Year\#TFPclas } \\
\text { s }\end{array}$ & $\begin{array}{c}\text { Firm; } \\
\text { Year\#TFPclas } \\
\text { s }\end{array}$ & $\begin{array}{c}\text { Firm; } \\
\text { Year\#TFPclas } \\
\text { s }\end{array}$ \\
\hline
\end{tabular}

Note: Firm-level panel fixed effect estimations including year fixed effects for each of two TFP classes (Top 10\%/Bottom 90\%). A \# indicates an interaction term. Standard errors clustered at the Si-Gun-Gu level in parenthesis. See text for data description and details on the empirical strategy.

Source: Authors' elaborations based on BvD ORBIS data.

To ensure the robustness of the results, Table A2 in the Annex reports estimations on a sample that excludes companies with less than 20 employees on average over the period. This has the effect of making the coverage of the ORBIS database more homogenous, as the share of firms not included in the database tends to be much lower for higher size classes $(\mathrm{Gal}, 2013)$. The second robustness test (Table A3) limits the sample to the same firms in each of the estimated specifications. To ensure the maximum number of 
observations for the estimation, all firms with available data are included in the above specifications. Some firms have missing information on some of the six dependent variables but not others; this means that they are included in some but not all specifications. Therefore, in the baseline estimations, the number of observations changes slightly across specifications depending on the availability of the dependent variable. Neither of the two robustness checks shows significant differences from the results reported above.

\section{Conclusion}

This paper depicts the change in transport infrastructure in Korea over a 16 year period that saw a rapid increase of the available road infrastructure. In particular the continued development of the expressway network - i.e. the part of the road network with the highest speed - increased the area and therefore the market that firms can access within a given amount of time. This paper develops an indicator that combines the area that residents can reach within a certain time of travel with population density to create a proxy for "accessibility", i.e. access to employment and consumption opportunities.

Results suggest that some types of incumbent firms were able to leverage opportunities provided by improvements in accessibility. In particular, the most productive frontier firms seem to have created benefits in terms of employment, output or productivity as accessibility improved. They also suggest that there was little displacement, with the exceptions of service sectors where employment increased in response to improved local accessibility (i.e. less than 60 minutes of driving) and declined for long distance accessibility (120-180 minute drives). This is in line with workers in service sectors benefitting disproportionately from agglomeration economies and knowledge spillovers and international evidence that tends to find negative effects on incumbents (e.g. Gibbons et al., 2012 for the United Kingdom).

It is important to note that the results presented in this paper are focused on incumbent firms. But access to expressways can also influence the decision of where to locate new enterprises. This relocation can create competition and is often essential in realising opportunities created by investments. Ahn, Kim and Ulfarsson (2015) consider the impact of the West Coast expressway, which was completed in 2001, on the location of manufacturing establishments. This work uses data for all new manufacturing establishments with at least five employees created between 1997 and 2006 in 2029 TL5 areas (towns and neighbourhoods, Dong, Eup, Myong) in cities and provinces close to the West Coast expressway. It shows that both the access to the existing and new expressway positively influences the likelihood that a manufacturing establishment opens in a neighbourhood. Most of these new establishments tend to choose locations near a slip road, but the strength of the attraction towards new infrastructure depends on the type of establishment.

The strongest impact of the West Coast expressway was for small manufacturing establishments with fewer than 10 employees. ${ }^{11}$ The average number of newly founded small firms increased by about $10 \%$ as the distance to the nearest West Coast expressway slip road was reduced by 28.5 kilometres - the average distance of TL5 areas in the study region to the West Coast expressway in 2006. More technology intensive manufacturing establishments favoured neighbourhoods with newly improved connectivity, while establishments operating in the low-tech sector chose locations close to existing expressways. The average number of new high tech manufacturing firms increased by more than $20 \%$ as the distance to the nearest West Coast expressway slip road was reduced by 28.5 kilometres. For medium low- and low-tech manufacturing firms the same improvement in connectivity resulted in increases of less than $10 \%$ in the average number of new establishments. In contrast, access to the existing highway network only increased the average number of low tech manufacturing firms. The same effect is evident for establishments with more than 30 employees. While some of these large (and low-tech) establishments can be fast growing newly founded firms, they are often relatively large new establishments that relocate production from other parts of the country. These results highlight that considering both incumbents and new entrants would provide a fuller picture of the impact of new road infrastructure on firms. In the context of this study, 
however, considering new entrants was not possible due to data limitations in the ORBIS database and has to be left to further research.

A recurring result is the negative relationship between improved accessibility and the value of fixed assets. One explanation is that manufacturing firms can reduce their local production capacity and facilities to house stocks as their connectivity to suppliers improves. This is partly supported by the lower reductions in fixed assets found for service sectors firms. If firms own the property where they are located, they might also find it valuable to sell off those holdings, realising profits from increased land values and freeing up capital for investment. To the extent that the more valuable holdings are allocated to a more productive use, this process can be productivity enhancing in the aggregate. These are, however, only conjectures and future work could aim to consider the asset channel in more detail, ideally supported by further external information such as land prices.

Further research could also aim to further alleviate endogeneity concerns in the empirical specification. While the panel fixed effects strategy accounts for a wide range of possible confounding factors, concerns might remain that time-varying factors might influence both firm performance and the change in accessibility. Eliminating such potential sources for bias could be achieved by developing instrumental variables for accessibility, i.e. variables that are correlated with accessibility but do not affect firm-level outcomes other than through their impact on accessibility. Academic papers have based such instruments on historical trade or road networks interacted with a suitable time-varying indicator, which might be a feasible strategy assuming sufficient historic data on Korea's road and trade networks could be gathered. ${ }^{12}$ Finally, a further expansion of this work could look at the effect on entrants, if suitable data sources were available. This would be particularly informative also to understand whether the effect found on incumbents is due to increased competition by new firms. 


\section{NOTES}

1. Territorial Level 3 (TL3) regions are small regions in OECD countries that correspond to administrative regions, with the exception of Australia, Canada, Germany, and the United States (OECD, 2013).

2. See MoF (2014) for data details.

3. See WHO (2015) for details.

4. See OECD (2015g) for the distribution of commuting time for major European cities.

5. Result from the OECD (2010c) Family Database, available at http://www.oecd.org/els/family/43199696.pdf, Estimates are based on time use survey data, and refer to the period 1999-2006 (for Korea the data are from 2004).

6. Assigning an average speed is of course a simplifying assumption. Detailed average speeds are not available for the whole road network and even where they are available, they vary substantially during the day, across days and weeks. The choice is therefore to use average speeds based on a 2013 study by the Geyonggi-do transport database center (GTDC, 2013).

7. For a detailed description of consolidation and related issues in ORBIS see Gal (2013) and Gonnard and Ragoussis (2013).

8. See e.g. Calvino, Criscuolo and Menon (2016).

9. See also Andrews, Criscuolo and Gal (2015) for evidence on the role of frontier firms for global productivity growth.

10. See e.g. Moretti (2004) for evidence on the differential impact of an increase in (skilled) labour supply for firms operating in high or low-tech. sectors.

11. See OECD (2016a) and Ahn, Kim and Ulfarsson (2015) for details on the discussed results.

12. See e.g. Duranton and Turner (2012) for an implementation of this strategy for the growth of cities. 


\section{REFERENCES}

Ahn, S., H. Kim and G.F. Ulfarsson (2015), "Transportation infrastructure investment and the location of new manufacturing: A Korean case study", mimeo.

Ahrend, R., E. Farchy, I. Kaplanis and A.C. Lembcke (2014), "What makes cities more productive?

Evidence on the role of urban governance from five OECD countries", OECD Regional

Development Working Papers, No. 2014/05, OECD Publishing, Paris,

http://dx.doi.org/10.1787/5jz432cf2d8p-en.

Ahrend, R. and A. Schumann (2014), "Does Regional Economic Growth Depend on Proximity to Urban Centres?", OECD Regional Development Working Papers, No. 2014/07, OECD Publishing, Paris, http://dx.doi.org/10.1787/5jz0t7fxh7wc-en.

Andrews, D., C. Criscuolo and P. Gal (2015), "Frontier Firms, Technology Diffusion and Public Policy: Micro Evidence from OECD Countries", OECD Productivity Working Papers, No. 2, OECD Publishing, Paris, http://dx.doi.org/10.1787/5jrq12q2jj7b-en.

Angrist, J.D. and J.-S. Pischke (2009), Mostly Harmless Econometrics: An Empiricist's Companion, Princeton University Press.

Baum-Snow, N. (2007), “Did Highways Cause Suburbanization?”, The Quarterly Journal of Economics, Vol. 122(2), pp. 775-805.

Bravo-Biosca, A., C. Criscuolo and C. Menon (2013), "What Drives the Dynamics of Business Growth?", OECD Science, Technology and Industry Policy Papers, No. 1, OECD Publishing, Paris, http://dx.doi.org/10.1787/5k486qtttq46-en.

Calvino, F., C. Criscuolo and C. Menon (2016), "No Country for Young Firms?: Start-up Dynamics and National Policies", OECD Science, Technology and Industry Policy Papers, No. 29, OECD Publishing, Paris, http://dx.doi.org/10.1787/5jm22p40c8mw-en.

Cervero, R. and C.D. Kang (2011), "Bus rapid transit impacts on land uses and land values in Seoul, Korea”, Transport Policy, Vol. 18(1), pp. 102-116.

Duranton, G. and D. Puga (2004), "Micro-foundations of urban agglomeration economies", in Henderson, J.V. and J.F. Thisse (eds.), Handbook of Regional and Urban Economics, Vol. 4, Ch. 48, pp. 2 063-2 117.

Duranton, G. and M.A. Turner (2012), "Urban growth and transportation", Review of Economic Studies, Vol. 79(4), pp. 1407-1440.

Gal, P. (2013), "Measuring Total Factor Productivity at the Firm Level using OECD-ORBIS", OECD Economics Department Working Papers, No. 1049, OECD Publishing, Paris, http://dx.doi.org/10.1787/5k46dsb251s6-en.

Gibbons, S., T. Lyytikäinen, H. Overman and R. Sanchis-Guarner (2012), "New Road Infrastructure: The Effects on Firms", SERC Discussion Paper, No. 117, Spatial Economics Research Centre.

Gonnard, E. and A. Ragoussis (2013), "The OECD-ORBIS database treatment and benchmarking procedures", unpublished manuscript. 
GTDC (2013), Traffic speed analysis of main roads in Gyeonggi-do in 2012 [translated from Korean], Geonggi-do Transport Database Center, Suwon-si, Gyeonggi-do, Korea.

Holl, A. (2014), "Highways and productivity in urban and rural locations", unpublished manuscript, available at: www.ipp.csic.es/sites/default/files/doc/cv/highways_Feb.pdf.

KTDB (2015), "Vehicle-kilometres by road type" [translated from Korean], Korea Transport Database, The Korea Transport Institute, http://www.ktdb.go.kr/ko/web/guest/420 (accessed 30 November 2015).

LandScan (2009), High Resolution Global Population Data Set (database), copyrighted by UT-Battelle, LLC, operator of Oak Ridge National Laboratory under contract No. DE-AC05-00OR22725 with the United States Department of Energy. The United States Government has certain rights in this Data Set. Neither ut-battelle, llc nor the United States Department of Energy, nor any of their employees, makes any warranty, express or implied, or assumes any legal liability or responsibility for the accuracy, completeness, or usefulness of the data set.

Michaels, G. (2008), "The Effect of Trade on the Demand for Skill: Evidence from the Interstate Highway System", The Review of Economics and Statistics, Vol. 90(4), pp. 683-701.

MoF (2014), "Current Status and Challenges of Infrastructure Development", Discussion Material for the Fiscal System Subgroup, Fiscal System Council, Tokyo, 20 October, available at: https://www.mof.go.jp/about mof/councils/fiscal_system council/sub-of fiscal system/proceedings Imaterial/zaiseia261020/01.pdf.

MOLIT (2015), Road work manual [only available in Korean], Ministry of Land, Infrastructure and Transport, Sejong special autonomous city, Korea, www.molit.go.kr/USR/BORD0201/m_34879/DTL.jsp?mode=view\&idx=30121 (accessed 20 August 2015).

Moretti, E. (2004), "Workers' education, spillovers, and productivity: Evidence from plant-level production functions", The American Economic Review, Vol. 94, No. 3, pp. 656-690.

OECD (2016a), Road Infrastructure, Inclusive Development and Traffic Safety in Korea, OECD Publishing, Paris, http://dx.doi.org/10.1787/9789264255517-en.

OECD (2016b), OECD Territorial Reviews: Japan 2016, OECD Publishing, Paris, http://dx.doi.org/10.1787/9789264250543-en.

Redding, S.J. and D.M. Sturm (2008), "The Costs of Remoteness: Evidence from German Division and Reunification", The American Economics Review, Vol. 98(5), pp. 1766-1797.

Sanchis-Guarner, R. (2014), "Driving up Wages: The Effects of Road Construction in Great Britain", unpublished manuscript, available at: http://personal.1se.ac.uk/sanchisg/Rosas_website/Research_files/Transport_labour_BA_short.pdf.

WHO (2015), Global status report on road safety 2015, World Health Organisation.

Wooldridge, J.M. (2009), "On estimating firm-level production functions using proxy variables to control for unobservables”, Economics Letters, Vol. 104(3), pp. 112-114. 


\section{ANNEX}

Table A.1. Classification of manufacturing sectors by technological intensity

\begin{tabular}{lll}
\hline Code & Description & Classification \\
C14 & Manufacture of wearing apparel & low-tech \\
C13 & Manufacture of textiles & low-tech \\
C22 & Manufacture of rubber and plastics products & low-tech \\
C16 & Manufacture of wood and of products of wood and cork, except furniture; & low-tech \\
& manufacture of articles of straw and plaiting materials & low-tech \\
C24 & Manufacture of basic metals & low-tech \\
C32 & Other manufacturing & low-tech \\
C31 & Manufacture of furniture & low-tech \\
C18 & Printing and reproduction of recorded media & low-tech \\
C15 & Manufacture of leather and related products & low-tech \\
C12 & Manufacture of tobacco products & low-tech \\
C25 & Manufacture of fabricated metal products, except machinery and equipment & low-tech \\
C17 & Manufacture of paper and paper products & low-tech \\
C10 & Manufacture of food products & low-tech \\
C11 & Manufacture of beverages & low-tech \\
C23 & Manufacture of other non-metallic mineral products & medium-low-tech \\
C28 & Manufacture of machinery and equipment n.e.c. & medium-low-tech \\
C30 & Manufacture of other transport equipment & medium-low-tech \\
C19 & Manufacture of coke and refined petroleum products & medium-high/high-tech \\
C26 & Manufacture of computer, electronic and optical products & medium-high/high-tech \\
C27 & Manufacture of electrical equipment & medium-high/high-tech \\
C20 & Manufacture of chemicals and chemical products & medium-high/high-tech \\
C29 & Manufacture of motor vehicles, trailers and semi-trailers & medium-high/high-tech \\
C21 & Manufacture of basic pharmaceutical products and pharmaceutical preparations & math \\
\hline & &
\end{tabular}


Table A.2. Robustness: Accessibility improvements within 0-180 minutes driving, firms with 20 employees or more

\begin{tabular}{|c|c|c|c|c|c|c|}
\hline & Employment & Wage bill & Gross output & Fixed assets & Labour prod. & MFP \\
\hline \multicolumn{7}{|c|}{ Panel A: Manufacturing } \\
\hline $0-180 \mathrm{~min}$ & 0.0259 & 0.0826 & 0.177 & $-0.751^{\star \star *}$ & 0.151 & $-0.0934^{* *}$ \\
\hline accessibility (In) & $(0.0972)$ & $(0.115)$ & $(0.157)$ & $(0.173)$ & $(0.115)$ & $(0.0473)$ \\
\hline Observations & 182,856 & 177,434 & 182,856 & 182,673 & 182,856 & 126,051 \\
\hline R-squared & 0.858 & 0.788 & 0.886 & 0.897 & 0.799 & 0.994 \\
\hline Fixed effects & Firm; year. & Firm; year. & Firm; year. & Firm; year. & Firm; year. & Firm; year. \\
\hline \multicolumn{7}{|c|}{ Panel A: Manufacturing } \\
\hline $0-180 \mathrm{~min}$ & -0.249 & 0.0968 & -0.0928 & -0.303 & 0.156 & 0.0478 \\
\hline accessibility (In) & $(0.156)$ & $(0.120)$ & $(0.182)$ & $(0.231)$ & $(0.126)$ & $(0.120)$ \\
\hline Observations & 150,078 & 146,934 & 150,078 & 149,755 & 150,078 & 66,171 \\
\hline R-squared & 0.838 & 0.812 & 0.891 & 0.928 & 0.878 & 0.990 \\
\hline Fixed effects & Firm; year. & Firm; year. & Firm; year. & Firm; year. & Firm; year. & Firm; year. \\
\hline
\end{tabular}

Note: Firm-level panel fixed effect estimations. Standard errors clustered at the Si-Gun-Gu level in parenthesis. See text for data description and details on the empirical strategy.

Source: Authors' elaborations based on BvD ORBIS data.

Table A.3. Robustness: Accessibility improvements within 0-180 minutes driving, constant sample across specifications

\begin{tabular}{|c|c|c|c|c|c|c|}
\hline & Employment & Wage bill & Gross output & Fixed assets & Labour prod. & MFP \\
\hline \multicolumn{7}{|c|}{ Panel A: Manufacturing } \\
\hline $0-180 \mathrm{~min}$ & 0.105 & 0.0686 & $0.272^{*}$ & $-0.691^{\star \star \star}$ & 0.167 & $-0.0944^{*}$ \\
\hline accessibility (In) & $(0.117)$ & $(0.128)$ & $(0.142)$ & $(0.208)$ & $(0.121)$ & $(0.0482)$ \\
\hline Observations & 125,154 & 125,154 & 125,154 & 125,154 & 125,154 & 125,154 \\
\hline R-squared & 0.843 & 0.794 & 0.876 & 0.885 & 0.806 & 0.994 \\
\hline Fixed effects & Firm; year. & Firm; year. & Firm; year. & Firm; year. & Firm; year. & Firm; year. \\
\hline \multicolumn{7}{|c|}{ Panel B: Services } \\
\hline $0-180 \mathrm{~min}$ & -0.325 & -0.00869 & -0.332 & -0.494 & -0.00671 & 0.0429 \\
\hline accessibility (In) & $(0.212)$ & $(0.187)$ & $(0.251)$ & $(0.311)$ & $(0.189)$ & $(0.124)$ \\
\hline Observations & 65,578 & 65,578 & 65,578 & 65,578 & 65,578 & 65,578 \\
\hline R-squared & 0.824 & 0.808 & 0.887 & 0.909 & 0.862 & 0.990 \\
\hline Fixed effects & Firm; year. & Firm; year. & Firm; year. & Firm; year. & Firm; year. & Firm; year. \\
\hline
\end{tabular}

Note: Firm-level panel fixed effect estimations. Standard errors clustered at the Si-Gun-Gu level in parenthesis. See text for data description and details on the empirical strategy.

Source: Authors' elaborations based on BvD ORBIS data. 